\title{
Pengaruh Beban Ransel Terhadap Keluhan Low Back Pain pada Mahasiswa FK-UMI Tahun 2018
}

Arni Isnaini Arfah ${ }^{1}$, Arina Fathiyyah Arifin ${ }^{2}$, A. Dhedie Prasatia Sam ${ }^{3}$, Imran Syafei ${ }^{4}$, Andi Nailah $^{5}$

${ }^{1}$ Dosen Bagian Fisiologi, Fakultas Kedokteran, Universitas Muslim Indonesia

${ }^{2}$ Dosen Bagian Histologi, Fakultas Kedokteran, Universitas Muslim Indonesia

${ }^{3}$ Dosen Bagian Orthopedi dan Traumatologi, Fakultas Kedokteran, Universitas Muslim Indonesia

${ }^{4}$ Dosen Bagian Kedokteran Fisik dan Rehabilitasi, Fakultas Kedokteran, Universitas Muslim Indonesia

${ }^{5}$ Program Sarjana Kedokteran, Fakultas Kedokteran, Universitas Muslim Indonesia

*Corresponding Author. E-mail: arniisaini.arfah@umi.ac.id, Mobile number: +62 852-5549-1100

\begin{abstract}
ABSTRAK
Latar belakang: Low back pain (LBP) merupakan salah satu gangguan muskuloskeletal yang paling sering diderita dan menjadi penghambat dalam melakukan aktivitas sehari-hari. Penggunaan ransel merupakan faktor terpenting yang menyebabkan nyeri punggung bawah di kalangan pelajar. Berat ransel telah meningkat secara signifikan karena perlunya membawa perlengkapan akademik. Hal ini menyebabkan peneliti tertarik untuk melakukan penelitian di bidang tersebut untuk mengetahui pengaruh berat beban ransel terhadap keluhan low back pain pada mahasiswa Fakultas Kedokteran Universitas Muslim Indonesia tahun 2018.

Metode: Penelitian ini merupakan penelitian analitik observasional dengan pendekatan cross sectional yang dilakukan secara online menggunakan kuesioner melalui google form di tempat responden masing-masing. Hasil: Dari 147 sampel, hasil yang didapatkan bahwa mahasiswa yang membawa beban ransel (carry less) $\leq$ $10 \%$ dari berat badan (beban ringan) dan tidak terjadi low back pain sebanyak 77 responden, minimal disability 29 responden, dan moderate disability 3 reponden. Sedangkan mahasiswa yang membawa beban ransel (carry less) $\geq 10 \%$ dari berat badan (beban berat) dan tidak terjadi low back pain 16 responden, minimal disability 21 responden, dan moderate disability 1 responden.

Kesimpulan: Hasil uji statistik Pearson Chi- Square menunjukan ada hubungan antara beban ransel dengan kejadian low back pain. Karena nilai significance lebih besar dari 0.1 sehingga terdapat hubungan antara berat beban ransel terhadap kejadian low back pain.
\end{abstract}

Kata kunci : Low back pain; berat beban; ransel

Article history: Received: 10 April 2021 Accepted: 30 April 2021

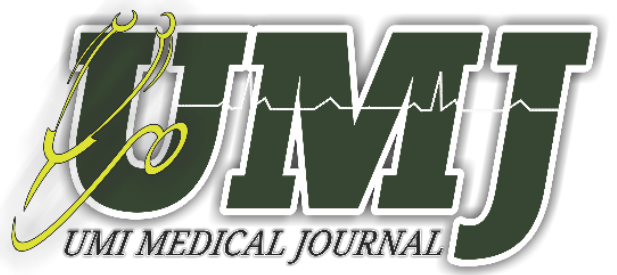

Published: 30 Juni 2021

Published by :

Fakultas Kedokteran

Universitas Muslim Indonesia

Phone:

+6282293330002
Address:

Jl. Urip Sumoharjo Km. 5 (Kampus II UMI)

Makassar, Sulawesi Selatan.

Email:

medicaljournal@umi.ac.id 


\section{ABTRACT}

Background: Low back pain (LBP) is one of the most common musculoskeletal disorders and becomes an obstacle to carrying out daily activities. The use of a backpack is the most important factor causing low back pain among students. Backpack weight has increased significantly due to the need to carry academic equipment. This causes researchers to be interested in conducting research in this field to determine the effect of backpack weight on complaints of low back pain in students of the Faculty of Medicine at the Muslim University of Indonesia in 2018.

Method: This research is an observational analytic study with a cross sectional approach which was conducted online using a questionnaire via google. form in the respective respondent's place.

Result: From 147 samples, the results showed that students who carried backpack loads (carry less) $\leq 10 \%$ of their body weight (light loads) and there were 77 respondents who did not experience low back pain, 29 respondents had minimal disability, and 3 respondents moderate disability. Meanwhile, students who carry backpack loads (carry less) $\geq 10 \%$ of their body weight (heavy loads) and 16 respondents do not experience low back pain, 21 respondents with minimal disability, and 1 respondent's moderate disability.

Conclusion: The results of the Pearson Chi-Square statistical test show that there is a relationship between backpack load and the incidence of low back pain. Because the significance value is greater than 0.1 , so there is a relationship between backpack weight and the incidence of low back pain.

Key words : Low back pain; heavy loads; backpack

\section{PENDAHULUAN}

Gangguan musculoskeletal merupakan cedera yang terjadi pada sendi, ligament, otot, saraf, tendon, dan struktur yang menyokong anggota tubuh, leher dan punggung. Gangguan musculoskeletal dapat disebabkan oleh infeksi, inflamasi,tumor, mekanis/fisiologis maupun cedera/trauma pada bagian terkena itu sendiri. Low back pain (LBP) merupakan salah satu gangguan musculoskeletal yang paling sering diderita dan menjadi penghambat dalam melakukan aktivitas sehari-hari. LBP juga dapat berpengaruh pada tingkat social dan ekonomi. Prevalensi terjadinya low back pain sebanyak 60\% sampai $70 \%$ pada negara industri (dengan prevalensi per tahunnya sebanyak 15\% sampai 45\%, pada orang dewasa sebanyak 5\% per tahun).(Dwiguno \& Setiadi, 2020)

Tulang belakang manusia terdiri dari struktur dan jaringan yang sangat spesifik yang bersama-sama menyediakan Range of Motion (ROM) dan kapasitas angkut yang cukup besar. Perubahan bentuk struktur ini berhubungan dengan bertambahnya usia, cedera, atau hal-hal lain yang memiliki pengaruh besar pada kualitas hidup. Low Back Pain atau nyeri punggung bawah merupakan masalah kesehatan dunia yang sangat umum, yang menyebabkan pembatasan aktivitas dan juga ketidakhadiran pembatasan kerja. Pada remaja, risiko nyeri punggung bawah mirip dengan orang dewasa, dengan tingkat prevalensi 70-80\% pada usia 20 tahun. (Wals, Emily, 2017; Patrianingrum et al., 2015; Delitto Anthony 2012)

Penyebab LBP sebagian besar (85\%) adalah nonspesifik, akibat kelainan pada jaringan lunak, berupa cedera otot, ligamen, spasme atau keletihan otot. Penyebab lain yang serius adalah spesifik antara lain, fraktur vertebra, infeksi dan tumor. Penggunaan ransel merupakan faktor terpenting yang menyebabkan nyeri punggung bawah di kalangan pelajar. Berat ransel telah meningkat secara signifikan karena perlunya membawa perlengkapan akademik. Terjadinya nyeri punggung dikaitkan dengan berat ransel lebih dari $15 \%$ 
UMI Medical Journal Vol.6 Issue:1 (Juni, 2021)

p-ISSN: 2548-4079/e-ISSN: 2685-7561

dari total massa tubuh dan periode waktu yang lama untuk membawa tas. Jenis ransel juga mempengaruhi low back pain di kalangan pelajar. Ransel dua tali adalah desain yang paling ergonomis. Membawa ransel di satu bahu dan bukannya kedua bahu juga meningkatkan risiko nyeri punggung karena penyimpangan postur. Demikian pula, cara membawa beban yang asimetris berkontribusi terhadap low back pain. (Amyra Natasha et al., 2018; Fitriana, Ruhaya, 2018)

Pelajar yang menggunakan tas punggung sudah menjadi hal yang umum pada saat ini. Dibandingkan dengan jenis tas lainnya, tas punggung merupakan jenis tas yang paling banyak digunakan. Penggunaan tas punggung yang tidak sesuai memiliki dampak negatif yang cukup besar bagi pengguna tas punggung. Dampak negatif tersebut antara lain dapat menimbulkan nyeri punggung,perubahan postur tubuh dan gaya berjalan, serta cidera. Dengan meningkatnya beban sekolah, biasanya membawa ransel yang lebih berat dari $10 \%$ dari berat badan secara teratur. Terlepas dari apakah orang itu membawa ransel di satu atau dua bahu dan apakah laki-laki atau perempuan, sakit punggung tetap dirasakan (Hendri, Et al, 2014; Hossain \& Tonima, 2017)

Fakultas Kedokteran Universitas Muslim Indonesia merupakan salah satu jurusan yang mayoritas mahasiswanya menggunakan ransel dan jam kuliah yang padat, sehingga berat beban ransel yang digunakan saat kuliah yang lama beresiko mengalami keluhan nyeri pada punggung bawah atau low back pain. Hal ini menyebabkan peneliti tertarik untuk melakukan penelitian di bidang tersebut.

Hasil penelitian dari 147 sampel didapatkan bahwa mahasiswa yang membawa beban ransel (carry less) $\leq 10 \%$ dari berat badan (beban ringan) dan tidak terjadi low back pain sebanyak 77 responden, minimal disability 29 responden, dan moderate disability 3 responden. Sedangkan mahasiswa yang membawa beban ransel (carry less) $\geq 10 \%$ dari berat badan (beban berat) dan tidak terjadi low back pain sebanyak 16 responden, minimal disability 21 responden, dan moderate disability 1 responden.

\section{METODE}

Penelitian ini merupakan penelitian analitik observasional dengan pendekatan cross sectional. Cakupan jenis penelitian ini mengukur semua variable penelitian hanya satu kali, pada satu saat. Jenis penelitian ini dipilih karena peneliti ingin mencari tahu mengenai hubungan antara berat beban ransel terhadap keluhan low back pain pada mahasiswa fakultas kedokteran Universitas Muslim Indonesia angkatan 2018. (simple random sampling).

Low back pain adalah salah satu gangguan musculoskeletal yang mempengaruhi fungsi tulang belakang. Penyebab paling umum adalah ketegangan otot, penyakit degeneratif, stenosis tulang belakang, herniasi diskus, ataupun tumor tulang belakang (jarang). Diagnosis low back pain dapat ditegakkan melalui anamnesis untuk mengidentifikasi kemungkinan pasien mengalami kompresi saraf, fraktur, atau penyakit sistemik yang mendasarinya. Pemeriksaan fisik dan neurologis tetap dilakukan . Pada pasien dengan nyeri punggung bawah yang menjalar ke ekstremitas bawah, dapat dilakukan straight leg-raising 
UMI Medical Journal Vol.6 Issue:1 (Juni, 2021)

p-ISSN: 2548-4079/e-ISSN: 2685-7561

test. Pasien dengan posisi berbaring telentang, pemeriksa secara progresif mengangkat kaki pasien dengan lutut ekstensi penuh. Tes positif apabila nyeri radikuler timbul saat kaki terangkat kurang dari 70 derajat.

Untuk menilai kejadian low back pain dapat dilakukan dengan modified oswestry low back pain questionnaire. Kuesioner ini telah dirancang untuk memberikan informasi kepada pemeriksa tentang bagaimana nyeri punggung telah mempengaruhi kemampuan penderita untuk mengelola dalam kehidupan sehari-hari. Terdapat 10 item penilaian, yaitu intensitas nyeri, perawatan diri, mengangkat beban, berjalan, duduk, berdiri, tidur, kehidupan sosial, berpergian, dan pekerjaan. Dari 10 pertanyaan tersebut, jumlahkan seluruh nilai yang didapat kemudian dihitung dalam rumus dan diinterpretasikan. Hasil $0 \%$ menunjukkan tidak terjadi low back pain, < 20\% minimal disability, 21-40\% moderate disability, 41-60\% severe disability, 61-80\% crippled, dan 81-100\% menunjukkan pasien sudah sangat tersiksa oleh nyeri yang timbul.

\section{HASIL}

Berdasarkan hasil penelitian yang dilakukan secara online menggunakan google form tentang hubungan berat beban ransel terhadap keluhan low back pain pada mahasiswa Angkatan 2018 ada 147 sampel yang memenuhi kriteria inklusi dan eksklusi. Adapun hasil yang diperoleh adalah sebagai berikut:

\section{Tabel 1. Karakteristik Responden}

\begin{tabular}{|c|c|c|c|}
\hline Variabel & Karakteristik Mahasiswa & Frekuensi & Persentase $(\%)$ \\
\hline \multirow{4}{*}{ - Kriteria responden } & Responden dengan nyeri haid & 60 & $25.4 \%$ \\
\hline & $\begin{array}{l}\text { Responden yang memiliki riwayat } \\
\text { penyakit tulang belakang }\end{array}$ & 24 & $10.2 \%$ \\
\hline & $\begin{array}{l}\text { Responden dengan nyeri haid dan } \\
\text { memiliki riwayat penyakit } \\
\text { tulang belakang }\end{array}$ & 5 & $2.2 \%$ \\
\hline & $\begin{array}{l}\text { Sampel (memenuhi kriteria } \\
\text { inklusi dan eksklusi) }\end{array}$ & 147 & $62.2 \%$ \\
\hline \multirow[t]{2}{*}{ - Jenis kelamin } & Laki - laki & 58 & $39.5 \%$ \\
\hline & Perempuan & 89 & $60.5 \%$ \\
\hline \multirow[t]{6}{*}{ - Umur } & 17 tahun & 1 & $0.7 \%$ \\
\hline & 18 tahun & 3 & $2.0 \%$ \\
\hline & 19 tahun & 29 & $19.7 \%$ \\
\hline & 20 tahun & 95 & $64.6 \%$ \\
\hline & 21 tahun & 16 & $10.9 \%$ \\
\hline & 22 tahun & 3 & $2.0 \%$ \\
\hline \multirow{5}{*}{$\begin{array}{ll}\text { - } & \text { Sejak kapan } \\
\text { menggunakan ransel }\end{array}$} & TK & 97 & $66 \%$ \\
\hline & SD & 45 & $30.6 \%$ \\
\hline & SMP & 1 & $0.7 \%$ \\
\hline & SMA & 1 & $0.7 \%$ \\
\hline & Kuliah & 3 & $2.0 \%$ \\
\hline
\end{tabular}

Tabel 1 menunjukkan bahwa terdapat 89 orang yang tidak memenuhi kriteria inklusi dan eksklusi, terdiri dari 60 orang yang sedang mengalami nyeri haid (25.4\%), 24 orang yang memiliki riwayat penyakit 
UMI Medical Journal Vol.6 Issue:1 (Juni, 2021)

p-ISSN: 2548-4079/e-ISSN: 2685-7561

tulang belakang $(10.2 \%)$, dan 5 orang yang sedang mengalami nyeri haid dan memiliki riwayat penyakit tulang belakang (2.2\%). Sedangkan sampel yang diperoleh yaitu 147 orang (62.2\%). Dari 147 responden yang diteliti, sebagian besar mahasiswa berjenis kelamin perempuan yaitu $60.5 \%$, sedangkan responden laki-laki 39.5\%.

Sebagian besar mahasiswa berada pada umur 20 tahun yaitu sebanyak 64.6\%. Sedangkan responden berumur 17 tahun sebanyak $0.7 \%$, umur 18 tahun sebanyak $2.0 \%$, umur 19 tahun sebanyak 19.7\%, umur 21 tahun sebanyak $10.9 \%$, dan umur 22 tahun $2.0 \%$.

Mayoritas mahasiswa menggunakan ransel sejak TK yaitu 66\%. Sedangkan responden yang menggunakan ransel sejal SD yaitu 30.6\%, responden yang menggunakan ransel sejak SMP $0.1 \%$, responden yang menggunakan ransel sejak SMA $0.1 \%$, dan responden yang menggunakan ransel pada saat kuliah $2.0 \%$.

Tabel 2. Distribusi frekuensi gambaran lama penggunaan ransel perhari dan berat beban ransel yang dibawa

\begin{tabular}{|c|c|c|c|}
\hline No. & Karakteristik Mahasiswa & Frekuensi & Persentase $(\%)$ \\
\hline & Lama penggunaan ransel perhar & & \\
\hline & $<1$ jam & & \\
\hline & $1-2$ jam & 64 & $43.5 \%$ \\
\hline \multirow[t]{6}{*}{1.} & 2-3 jam & 53 & $36.1 \%$ \\
\hline & $>3$ jam & 13 & $8.8 \%$ \\
\hline & & 17 & $11.6 \%$ \\
\hline & Jumlah & 147 & $100 \%$ \\
\hline & Berat beban ransel & & \\
\hline & $\begin{array}{l}\leq 10 \% \text { dari berat badan (beban } \\
\text { ringan) }\end{array}$ & 109 & $74.1 \%$ \\
\hline \multirow[t]{2}{*}{2.} & $\begin{array}{l}\geq 10 \% \text { dari berat badan (beban } \\
\text { berat) }\end{array}$ & 38 & $25.9 \%$ \\
\hline & Jumlah & 147 & $100 \%$ \\
\hline
\end{tabular}

Tabel 2 menunjukkan bahwa lama penggunaan ransel perhari mayoritas $<1$ jam $43.5 \%$, sedangkan penggunaan ransel 1-2 jam 36.1\%, penggunaan ransel 2-3 jam 8.8\% dan penggunaan ransel $>3$ jam $11.6 \%$. Untuk berat beban ransel mayoritas responden membawa beban $\leq 10 \%$ dari berat badan (beban ringan) $74.1 \%$ sedangkan beban $\geq 10 \%$ dari berat badan (beban berat) $25.9 \%$.

Tabel 3. Distribusi frekuensi gambaran kejadian low back pain

\begin{tabular}{llll}
\hline No. & Kejadian low back pain & Jumlah & Persentase (\%) \\
\hline 1. & Tidak terjadi $(0 \%)$ & 93 & $63.3 \%$ \\
2. & Minimal Disability (1-20\%) & 50 & $34 \%$ \\
3. & Moderate Disability $(21-40 \%)$ & 4 & $2.7 \%$
\end{tabular}


UMI Medical Journal Vol.6 Issue:1 (Juni, 2021)

p-ISSN: 2548-4079/e-ISSN: 2685-7561

\begin{tabular}{llll} 
4. Severe Disability (41-60\%) & 0 & $0 \%$ \\
5. Crippled (61-80\%) & 0 & $0 \%$ \\
6. Sangat tersiksa oleh nyeri (81- & 0 & $0 \%$ \\
& & \\
\hline 100\%) & Jumlah & 147 & $100 \%$
\end{tabular}

Tabel 3 menunjukkan bahwa sebagian besar responden tidak mengalami low back pain 63.3\%, sedangkan responden yang mengalami minimal disability $34 \%$ dan moderate disability $2.7 \%$.

\section{Tabel 4. Analisis Data Hubungan berat beban ranseldengan kejadian low back pain}

\begin{tabular}{|c|c|c|c|c|}
\hline \multirow{2}{*}{$\begin{array}{l}\text { Kategori } \\
\text { Berat beban ransel }\end{array}$} & \multicolumn{3}{|c|}{ Kejadian low back pain } & \multirow[b]{2}{*}{ Total } \\
\hline & $\begin{array}{l}\text { Tidak } \\
\text { terjadi }\end{array}$ & $\begin{array}{l}\text { Minimal } \\
\text { disability }\end{array}$ & $\begin{array}{l}\text { Moderate } \\
\text { disability }\end{array}$ & \\
\hline \multicolumn{5}{|c|}{$\leq 10 \%$ dari berat badan } \\
\hline (beban ringan) & 77 & 29 & 3 & 109 \\
\hline \multicolumn{5}{|c|}{$\geq 10 \%$ dari berat badan } \\
\hline (beban berat) & 16 & 21 & 1 & 38 \\
\hline$\overline{\text { Total }}$ & 93 & 50 & 4 & 147 \\
\hline
\end{tabular}

Tabel 4 menggambarkan hubungan beban ransel (carry less) dengan kejadian low back pain pada mahasiswa Fakultas Kedokteran Universitas Muslim Indonesia Angkatan 2018. Hasil yang didapatkan bahwa mahasiswa yang membawa beban ransel (carry less) $\leq 10 \%$ dari berat badan (beban ringan) dan tidak terjadi low back pain sebanyak 77 responden, minimal disability 29 responden, dan moderate disability 3 reponden. Sedangkan mahasiswa yang membawa beban ransel (carry less) $\geq 10 \%$ dari berat badan (beban berat) dan tidak terjadi low back pain 16 responden, minimal disability 21 responden, dan moderate disability 1 responden.

\begin{tabular}{|c|c|c|c|}
\hline \multicolumn{4}{|c|}{ Chi-Square Tests } \\
\hline & Value & $\mathrm{df}$ & $\begin{array}{c}\text { Asymptotic } \\
\text { Significance (2- } \\
\text { sided) }\end{array}$ \\
\hline Pearson Chi-Square & $10.432^{a}$ & 2 & .005 \\
\hline Likelihood Ratio & 10.094 & 2 & .006 \\
\hline Linear-by-Linear Association & 7.704 & 1 & .006 \\
\hline $\mathrm{N}$ of Valid Cases & 147 & & \\
\hline
\end{tabular}

Berdasarkan data output berikut diketahui nilai Asymp. Sig. 2-sided pada uji Pearson Chi-Square adalah sebesar 0.005 dapat disimpulkan bahwa ada hubungan antara beban ransel dengan kejadian low back pain pada mahasiswa Fakultas Kedokteran Univeristas Muslim Indonesia Angkatan 2018. karena 
UMI Medical Journal Vol.6 Issue:1 (Juni, 2021)

p-ISSN: 2548-4079/e-ISSN: 2685-7561

nilai Asymp. Sig. 2-sided $0.005<0.05$ sehingga terdapat hubungan antara berat beban ransel terhadap kejadian low back pain. Pada table output diatas diketahui nilai chi-square hitung $10.432>$ nilai chi-square table 1.386 sehingga dapat diartikan "Ada hubungan antara beban ransel dengan kejadian low back pain pada mahasiswa Fakultas Kedokteran Univeristas Muslim Indonesia Angkatan 2018”.

\section{PEMBAHASAN}

Penelitian yang dilakukan terhadap 147 responden didapatkan hasil bahwa terdapat hubungan antara berat beban ransel dengan kejadian low back pain.

Beban ransel (carry less) yang diteliti adalah tidak membawa ransel dengan berat melebihi dari proporsi total berat tubuh, berat benda yang dibawa oleh tubuh sebaiknya tidak melebihi $10 \%$ dari total berat tubuh. Jenis ransel juga mempengaruhi low back pain di kalangan pelajar. Ransel dua tali adalah desain yang paling ergonomis. Tas selempang dan dipegang dengan tangan dapat menyebabkan tekanan dan ketegangan pada otot-otot punggung karena distribusi beban yang tidak seimbang antara bahu.

Roller bags juga berkontribusi terhadap nyeri punggung bawah karena perubahan postur yang tidak benar selama penggunaannya. Membawa ransel di satu bahu dan bukannya kedua bahu juga meningkatkan risiko nyeri punggung karena penyimpangan postur. Demikian pula, cara membawa beban yang asimetris berkontribusi terhadap low back pain. Banyak peminat yang menggunakan tas ransel karena tas ini lebih praktis dan memiliki daya tampung lebih besar. (Amyra Natasha et al., 2018; Hendri et al., 2014; Dumondor et al., 2015).

Stress mekanik yang terjadi dalam jangka waktu lama ini menyebabkan timbulnya suatu reaksi pada jaringan otot untuk menopang beban yang bertambah, sehingga menyebabkan terjadinya perubahan pada bentuk sel, membran sel, konsentrasi ion dan munculnya integrin-integrin di jaringan. Integrin merupakan reseptor transmembran yang memediasi terjadinya ikatan antara sel dengan matriks ekstraseluler. Integrin juga dapat menginduksi terjadinya poliferasi sel, diferensiasi sel dan perbaikan matriks. Integrin juga dapat berikatan dengan kolagen, fibronektin dan laminin ini dapat menginduksi terjadinya proliferasi sel dan pembentukan matriks pada rawan sendi. Selain itu juga dapat memediasi pembentukan kartilago menjadi abnormal. Membawa tas yang berat menyebabkan perubahan postur tubuh. Perubahan postur ini dapat menyebabkan nyeri punggung dan cedera dengan menekan ligamen atau otot tulang belakang atau dengan mengubah gaya yang bekerja pada diskus intervertebralis. (Hendri et al., 2014)

Menurut Brackley dan Stevenson beban maksimal tas punggung yang ideal adalah 10-20\% dari berat badan. Sedangkan ada juga penelitian yang menetapkan presentase yang lebih kecil yaitu kurang dari $10 \%$. Dalam penelitian ini digunakan kriteria tas punggung berat dengan bobot tas $\geq 10 \%$ dari berat badan. Alasannya adalah beban mekanik yang dapat menimbulkan stress mekanik pada setiap orang dengan berat badan yang berbeda tentunya tidak sama. Dan kriteria ini dapat mengakomodir hal tersebut.(Faturachman, 2015) 


\section{KESIMPULAN}

Berdasarkan penelitian mengenai pengaruh berat beban ransel terhadap keluhan low back pain, maka peneliti dapat menyimpulkan hal sebagai berikut: Sebagian besar responden berjenis kelamin perempuan yaitu $60.5 \%$ dan sebagian besar responden berada pada umur 20 tahun yaitu 64.6\%. Lama penggunaan ransel mayoritas mahasiswa menggunakan ransel sejak TK yaitu 66\%. Data responden berdasarkan penggunaan ransel perhari mayoritas $<1$ jam 43.5\%, dan untuk berat beban ransel mayoritas responden membawa beban ransel $\leq 10 \%$ dari berat badan (beban ringan) $74.1 \%$. Terdapat hubungan antara beban ransel dengan kejadian low back pain pada mahasiswa Fakultas Kedokteran Universitas Muslim Indonesia Angkatan 2018.

\section{SARAN}

Saran bagi setiap mahasiswa Fakultas Kedokteran Universitas Muslim Indonesia sebaiknya memaksimalkan penggunaan loker yang telah disediakan agar tidak sekaligus membawa beban yang terlalu berat selama berkegiatan di kampus. Pertimbangkan juga mengenai faktor lain yang dapat menyebabkan low back pain, seperti posisi duduk dan lama duduk selama perkuliahan, atau penggunaan ransel yang tidak ergonomis. Bagi peneliti yang ingin melakukan penelitian yang sama, sebaiknya menggunakan variable Berat Badan Ideal (BBI) agar menyesuaikan dengan berat beban yang dibawa oleh setiap orang.

\section{DAFTAR PUSTAKA}

1. Amyra Natasha, A., Ahmad Syukri, A., Siti Nor Diana, M. K., Ima-Nirwana, S., \& Chin, K. Y. (2018). The association between backpack use and low back pain among pre-university students: A pilot study. Journal of Taibah University Medical Sciences, 13(2), 205-209. https://doi.org/10.1016/j.jtumed.2017.06.005

2. Delitto, Anthony. Low Back Pain Clinical Practice Guideline Linked to the International Classification of Functioning, Disability, and Health from the Orthopaedic Section of the American Physical Therapy Association. Journal of orthopaedic and sports physical therapy Vol. 42 No.4. pp 11-12. 2012

3. Dumondor, S. V., Angliadi, E., \& Sengkey, L. (2015). Hubungan Penggunaan Ransel Dengan Nyeri Punggung Dan Kelainan Bentuk Tulang Belakang Pada Siswa Di Smp Negeri 2 Tombatu. ECliniC, 3(1), 1-5. https://doi.org/10.35790/ecl.3.1.2015.6824

4. Dwiguno, M. G., \& Setiadi, T. H. (2020). Hubungan beban tas punggung terhadap low back pain pada pelajar kelas 3 SMA Kolese Gonzaga Angkatan 2015. 2(2), 321-324.

5. F.M.A Hossain, Masuda. A Study on the Effects of Heavy Backpack and Development of a Preventative Prototype. Hindawi Journal of Sensors. 2017

6. Faturachman, R. (2015). Hubungan antara kebiasaan menggunakan tas punggung berat dan kejadian Low Back Pain (LBP) pada mahasiswa program studi pendidikan dokter FKIK UIN Syarif Hidayatullah Jakarta. 
p-ISSN: 2548-4079/e-ISSN: 2685-7561

7. Fitriana, Ruhaya. Low Back Pain. Kementerian Kesehatan Republik Indonesia. 2018Hossain, F. M. A., \& Tonima, M. A. (2017). A Study on the Effects of Heavy Backpack and Development of a Preventative Prototype. Journal of Sensors, 2017. https://doi.org/10.1155/2017/9419373

8. Hendri, Etra Fianus, Pristiana, Ari, Karim Darwin. Hubungan Penggunaan Backpack dengan Kejadian Low Back Pain pada Mahasiswa Universitas Riau. JOM PSIK Vol.1 No.2. pp. 1.2014

9. Mario,Haming. Hubungan Beban Tas Punggung terhadap Low Back Pain pada Pelajar Kelas 3 SMA Kolese Gonzaga Angkatan 2015. Tarumanagara Medical Journal Vol.2, No.2, 321-324, April 2020

10. Stefany, Engeline, Lidwina. Hubungan Penggunaan Ransel Dengan Nyeri Punggung dan Kelainan Bentuk Tulang Belakang Pada Siswa di Smp Negeri 2 Tombatu. Jurnal e-Clinic Volume 3 Nomor 1. 2015

11. Patrianingrum, M., Oktaliansah, E., \& Surahman, E. (2015). Prevalensi dan Faktor Risiko Nyeri Punggung Bawah di Lingkungan Kerja Anestesiologi Rumah Sakit Dr. Hasan Sadikin Bandung. Jurnal Anestesi Perioperatif, 3(1), 47-56. https://doi.org/10.15851/jap.v3n1.379

12. Walsh, Emily. Finite Element Analysis Section I Chapter 11. Elsevier. Pp.168. 2017 